Original Article

\title{
FORMULATION AND EVALUATION OF FAST DISSOLVING FILMS OF ELETRIPTAN HYDROBROMIDE
}

\author{
K. PALLAVI, T. PALLAVI \\ G. Pulla Reddy College of Pharmacy, Osmania University \\ Email: pallavi.trivedi44@gmail.com \\ Received: 27 Nov 2016, Revised and Accepted: 23 Jan 2017
}

\section{ABSTRACT}

Objective: The main aim of the present research was to develop an oral fast dissolving polymeric film (FDF) with good mechanical properties, faster disintegration and dissolution when placed on the tongue.

Methods: Eletriptan hydrobromide is prescribed for the treatment of mild to a moderate migraine. The polymers selected for preparing films were Pullulan, Maltodextrin (MDX), Acacia, Sodium alginate (SA), Locust bean gum (LBG), Guar gum (GG), Xanthan gum (XG), Polyvinyl alcohol (PVA), Polyvinyl pyrrolidine (PVP), Hydroxyl propyl methyl cellulose (HPMC) E5, and HPMC E15. Twelve sets of films FN1-FN12 were prepared by solvent casting method with Pullulan and combination of Acacia, MDX, SA, LBG, GG, XG, PVA, PVP, HPMC E5 and HPMC E15. Five sets of films FS1-FS5 were prepared using synthetic polymers like PVA, PVP, HPMC E5 and HPMC E15.

Results: From all the prepared polymer formulations, FN2, FN8, and FS3 were selected based on disintegration time, and drug release and amongst this three FN2 was optimised based on its disintegration time (D. T). The percent drug release of the optimised film was compared with the percent release of the pure drug.

Conclusion: The optimised formulation had a D. T of $16 \mathrm{~s}$ and a percent drug release of $97.5 \%$ in $10 \mathrm{~min}$ in pH 6.8 phosphate buffer and $100.6 \%$ drug release in $10 \mathrm{~min}$ in $0.1 \mathrm{~N} \mathrm{HCl}$.

Keywords: oral FDFs, Pediatric, Geriatric, Dysphasia

(C) 2016 The Authors. Published by Innovare Academic Sciences Pvt Ltd. This is an open access article under the CC BY license (http://creativecommons.org/licenses/by/4.0/) DOI: http://dx.doi.org/10.22159/ijcpr.2017v9i2.17386

\section{INTRODUCTION}

The oral route is one of the oldest routes which is used for conventional and novel drug delivery. The main reason for this route being the highly preferred is ease of administration. FDFs, a new drug delivery system for the oral delivery of the drugs, was developed in late 1970's based on the technology of the transdermal patch. These were developed as an alternative to tablets, capsules, and syrups for pediatric and geriatric patients who experience difficulties in swallowing traditional oral solid-dosage forms [1]. By definition, "a solid dosage form that dissolves or disintegrates quickly in the oral cavity, resulting in solution or suspension without the need for administration of water is known as an oral fastdispersing dosage form"[2].

The novel technologies of oral fast-dispersing dosage forms are also known as fast dissolve, rapid dissolve, rapid melt and quick disintegrating systems. However, the function and concept of all these dosage forms are similar. These fast dissolving systems are used in the condition called Dysphasia (difficulty in swallowing), this is common among all age groups but especially in geriatric and pediatric patients [3]

Special features of FDFs $[4,5]$

- Thin, elegant film

- Available in various sizes and shapes

- Unobstructive

- Excellent mucoadhesion

- Fast disintegration

- Rapid release

Advantages of oral FDFs [6-9]

- Rapid onset of action and increased bioavailability.
- Suitability for old patients, who experience difficulties in swallowing, mentally ill, the developmentally disable and the patients who are uncooperative, or are on reduced liquid intake plans or are nauseated.

- Avoidance of water facilitating to use even in travelling

- Rapid disintegration than oral disintegrating tablet due to larger surface area.

- Beneficial in cases such as motion sickness, acute pain, episodes of allergic attack or coughing, where an ultra-rapid onset of action required.

- The oral or buccal mucosa being highly vascularised, drugs can be absorbed directly and can enter the systemic circulation without undergoing first pass hepatic metabolism. This advantage can be exploited in preparing products with the improved oral bioavailability of molecules that undergo first pass effect.

- The risk of choking or suffocation during oral administration of conventional formulation due to physical obstruction is avoided, thus providing improved safety.

- The sublingual and buccal delivery of a drug via thin film has the potential to improve the onset of action, lower the dosing, and enhance the efficacy and safety profile of the medicament.

- Delivery can also be terminated easily if required.

Disadvantages of oral FDFs $[10,11]$

- Drugs which are unstable at buccal pH cannot be administered.

- Drugs which irritate the mucosa cannot be administered by this route.

- Drug with small dose requirement can only be administered.

- Most of the drugs are bitter in taste needs taste masking. 
- FDF's are fragile and must be protected from water, so it needs special packaging.

\section{MATERIALS AND METHODS}

Eletriptan hydrobromide was used as an active ingredient, acacia, maltodextrin, sodium alginate, locust bean gum, xanthan gum, guar gum, HPMC E5, E15, PVA, PVP were used as water soluble polymers. Mannitol used as a sweetening agent and propylene glycol as a plasticizer. All polymers, propylene glycol, Mannitol and Glycerol, were procured from SD Fine chemicals Ltd. All other chemicals used were of analytical grade.

\section{Formulation of FDFs}

The general methods used to prepare FDFs are semisolid casting, solvent casting, hot melt extrusion, solid dispersion and rolling. In the present study, the FDF's were prepared using solvent casting method [10]. The casting solution was prepared by mixing polymer solution with drug, plasticizer, sweetener and flavor. The resulting solution was deaerated by sonication, then poured into appropriate moulds and dried to obtain the films. The final dosage form was cut into strips
$(2 \times 2 \mathrm{~cm})$ which contained the required amount of drug $(20 \mathrm{mg})$. Different formulations were prepared by varying the polymers and plasticizer concentrations (table 1 and 2). The prepared films were then evaluated for thickness, folding endurance, weight variation, disintegration time, dissolution time and drug content.

\section{Evaluation of films}

\section{Standard curve of eletriptan hydrobromide}

The standard curve of EHBR was obtained in two different mediums $6.8 \mathrm{pH}$ phosphate buffer and $0.1 \mathrm{~N} \mathrm{HCl} .100 \mathrm{mg}$ of EHBR was dissolved in $10 \mathrm{ml}$ of $6.8 \mathrm{pH}$ phosphate buffer and another $100 \mathrm{mg}$ of drug was dissolved in $0.1 \mathrm{~N} \mathrm{HCl}$, then the volume was made up to $100 \mathrm{ml}$ with respective mediums. $10 \mathrm{ml}$ of the above solutions were diluted up to $100 \mathrm{ml}$ with buffer and $0.1 \mathrm{~N} \mathrm{HCl}$ respectively. From this solution, $1 \mathrm{ml}$ was taken, and volume was made up to $100 \mathrm{ml}$ (1 $\mu \mathrm{g} / \mathrm{ml}$ ). Then by serial dilution, solutions with concentrations 2 $\mu \mathrm{g} / \mathrm{ml}, 4 \mu \mathrm{g} / \mathrm{ml}, 6 \mu \mathrm{g} / \mathrm{ml}, 8 \mu \mathrm{g} / \mathrm{ml}, 10 \mu \mathrm{g} / \mathrm{ml}, 12 \mu \mathrm{g} / \mathrm{ml}, 14 \mu \mathrm{g} / \mathrm{ml}$ and $16 \mu \mathrm{g} / \mathrm{ml}$ were prepared. Absorbance was measured on a Shimadzu Double Beam Spectrophotometer (UV1601) at $222.0 \mathrm{~nm}$ (table 3, 4).

Table 1: Composition of different films made of natural polymers

\begin{tabular}{|c|c|c|c|c|c|c|c|c|c|c|c|c|}
\hline Ingredients & FN1 & FN2 & FN3 & FN4 & FN5 & FN6 & FN7 & FN8 & FN9 & FN 10 & FN 11 & FN 12 \\
\hline EHBR & 140 & 140 & 140 & 140 & 140 & 140 & 140 & 140 & 140 & 140 & 140 & 140 \\
\hline PULLULAN* & 2 & 2 & 2 & 2 & 2 & 2 & 2 & 2 & 2 & 2 & 2 & 2 \\
\hline ACACIA* & 0.5 & - & - & - & - & - & 1 & - & - & - & - & - \\
\hline MALTO-DEXTRIN* & - & 1 & - & - & - & - & - & 2 & - & - & - & \\
\hline LOCUST BEANGUM* & - & - & 0.5 & - & - & - & - & - & 1 & - & - & - \\
\hline SODIUM ALGINATE* & - & - & - & 0.5 & - & - & - & - & - & 1 & - & - \\
\hline GUAR GUM* & - & - & - & - & .25 & - & - & - & - & - & .50 & - \\
\hline XANTHAN GUM* & - & - & - & - & & 0.5 & - & - & - & - & - & .75 \\
\hline MANNITOL* & 20 & 20 & 20 & 20 & 20 & 20 & 20 & 20 & 20 & 20 & 20 & 20 \\
\hline PROPYLENEGLYCOL** & 10 & 10 & 10 & 10 & 10 & 10 & 10 & 10 & 10 & 10 & 10 & 10 \\
\hline WATER & 10 & 10 & 10 & 10 & 10 & 10 & 10 & 10 & 10 & 10 & 10 & 10 \\
\hline
\end{tabular}

NOTE: All the ingredients were dissolved in $10 \mathrm{ml}$ distilled water, EHBR-Eletriptan hydrobromide in mg; FN-Formulations with natural polymers, $*$ are in $\% \mathrm{w} / \mathrm{v}$; $*$ is in $\% \mathrm{w} / \mathrm{w}$ of the polymer.

Table 2: Preparation of oral films using combination of various synthetic polymers

\begin{tabular}{|c|c|c|c|c|c|}
\hline Ingredients & FS1 & FS2 & FS3 & FS4 & FS5 \\
\hline EHBR & 140 & 140 & 140 & 140 & 140 \\
\hline PVA* & 3 & 1.75 & - & - & - \\
\hline PVP* & 2 & - & - & - & 2 \\
\hline HPMC E5* & - & 1.75 & 3 & 1 & 3 \\
\hline HPMC E15* & - & - & - & 2 & - \\
\hline Mannitol* & 0.2 & 0.2 & 0.2 & 0.2 & 0.2 \\
\hline Propylene glycol** & - & 0.2 & 0.5 & - & 0.2 \\
\hline PEG 400* & 0.2 & - & - & 0.3 & - \\
\hline Water & 10 & 10 & 10 & 10 & 10 \\
\hline
\end{tabular}

${ }^{*}$-are in $\% \mathrm{w} / \mathrm{v}$; ${ }^{* *}$ is in $\% \mathrm{w} / \mathrm{w}$ of polymer.

Table 3: Standard graph of EHBR in pH 6.8 Phosphate buffer

\begin{tabular}{ll}
\hline Concn (ug/ml) & Absorbance (mean \pm SD) \\
\hline 0 & 0 \\
2 & $0.178 \pm 0.0027$ \\
4 & $0.348 \pm 0.015$ \\
6 & $0.503 \pm 0.013$ \\
8 & $0.684 \pm 0.027$ \\
10 & $0.829 \pm 0.036$ \\
12 & $0.981 \pm 0.024$ \\
14 & $1.144 \pm 0.0051$ \\
\hline
\end{tabular}

$\mathrm{n}=6$

\section{Drug-excipients compatibility study by FT-IR}

EHBR compatibility with excipients was studied by FT-IR spectroscopy. From the spectra of the EHBR, it was observed that the main functional groups of the molecule were aromatic phenyl with sulfone and amide. The most intensive peak was observed at $1140 \mathrm{~cm}-1$ which were due to $\mathrm{C}-\mathrm{N}$ bending in the structure of EHBR. Another sharp peak was seen at $1640 \mathrm{~cm}-1$ 
which indicated the presence of $\mathrm{C}=\mathrm{C}$ (phenyl group), peak at $1305 \mathrm{~cm}-1$ was due to sulfone moiety. A peak at $3245 \mathrm{~cm}-1$ indicated the presence of $\mathrm{N}-\mathrm{H}$ stretch, $\mathrm{N}-\mathrm{H}$ bending was seen at $1480 \mathrm{~cm}-1$, and a peak at $528 \mathrm{~cm}^{-1}$ was due to the presence of bromide group as seen in fig. 3 .

From the FTIR spectra as seen in fig 4, it is very clear that the drug is compatible with pullulan and Maltodextrin as all the characteristic peaks of drug were retained. Hence there is no incompatibility between the drug and these excipients.

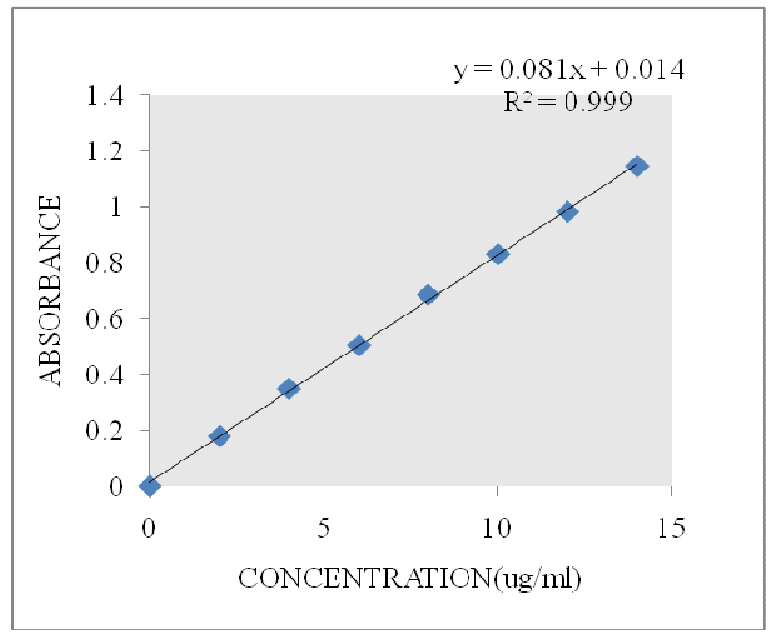

Fig. 1: Standard graph of EHBR in pH 6.8 phosphate buffer
Table 4: Standard graph of EHBR in $0.1 \mathrm{~N} \mathrm{HCl}$

\begin{tabular}{ll}
\hline Concn $(\mathbf{u g} / \mathbf{m l})$ & Absorbance (mean $\mathbf{S D})$ \\
\hline 0 & 0 \\
2 & $0.210 \pm 0.0061$ \\
4 & $0.357 \pm 0.0092$ \\
6 & $0.512 \pm 0.0115$ \\
8 & $0.652 \pm 0.0030$ \\
10 & $0.828 \pm 0.0035$ \\
12 & $0.98 \pm 0.001$ \\
14 & $1.15 \pm 0.002$ \\
\hline
\end{tabular}

$\mathrm{n}=6$

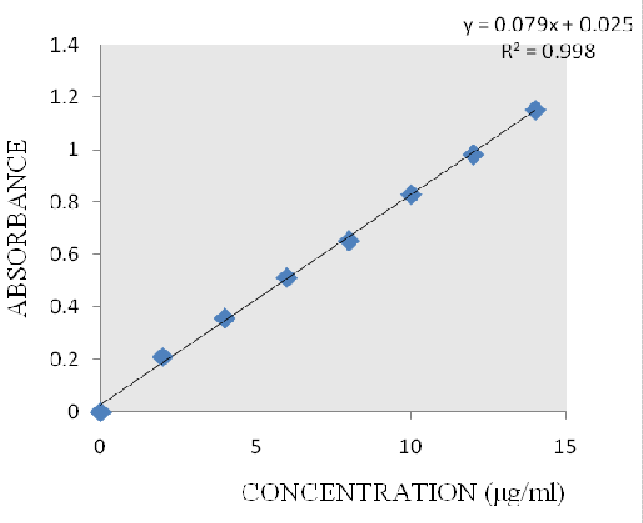

Fig. 2: Standard graph of EHBR in $0.1 \mathrm{~N} \mathrm{HCl}$

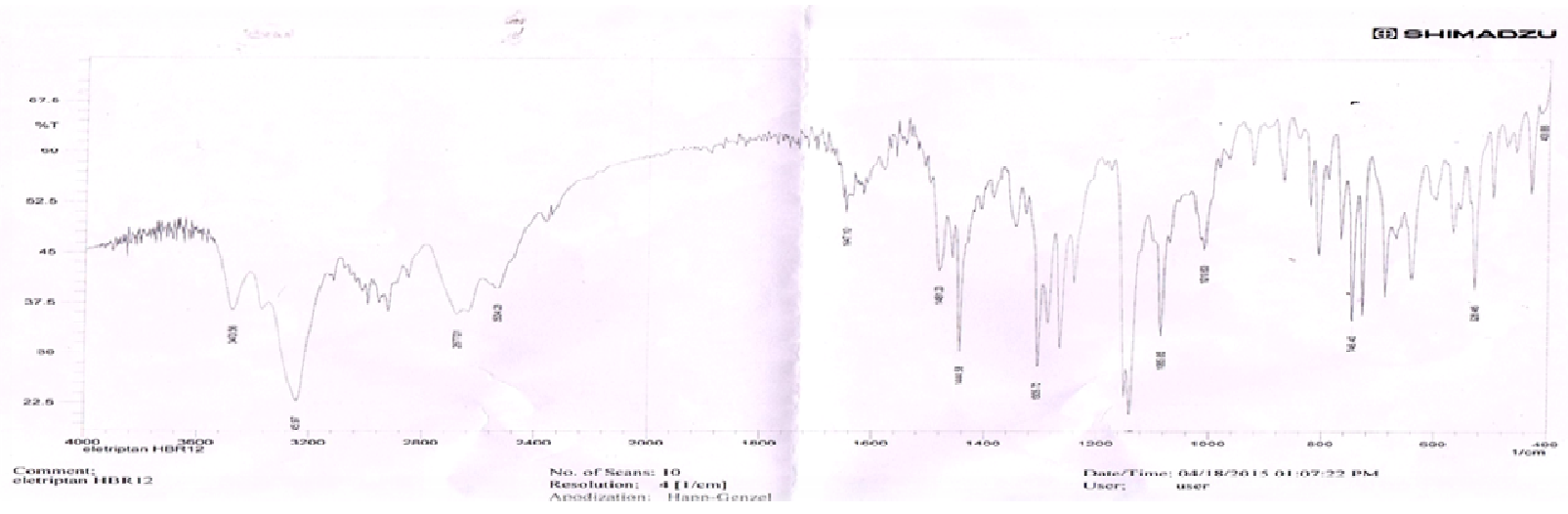

Fig. 3: FTIR spectrum of pure drug

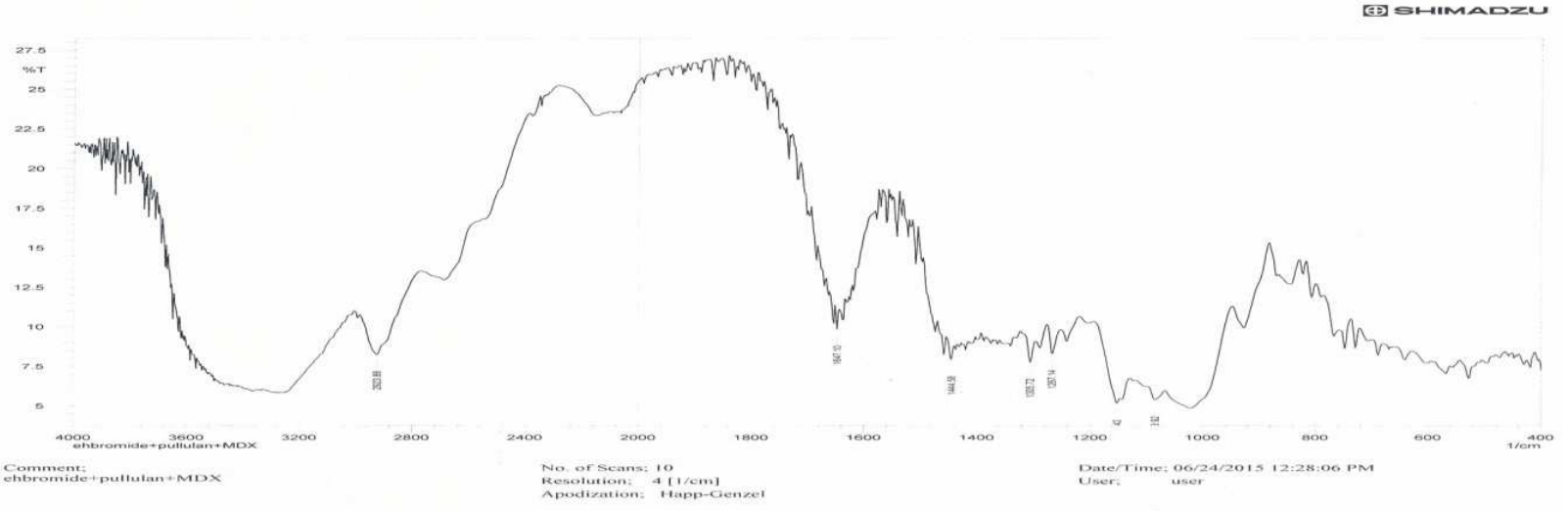

Fig. 4: FTIR spectrum of EHBR, pullulan and maltodextrin 


\section{Weight variation of the film}

The casted film was cut into various $2 \times 2 \mathrm{~cm}$ films from different locations. The weight of each film strip was taken and the weight variation was calculated.

\section{Thickness of the film}

The thickness of the film was measured by using screw gauge at various points of film and the average thickness was calculated.

\section{Folding endurance}

The folding endurance is expressed as the number of folds required for developing visible cracks or breaking any given film. This gives an indication of brittleness or flexibility of the film. A $2 \times 2 \mathrm{~cm}$ strip was subjected to this test by folding the film at the same point repeatedly several times until a visible crack was observed.

\section{Disintegration time}

Disintegration time study was slightly modified to mimic the in vitro and in vivo conditions. For the study, $2 \times 2 \mathrm{~cm}$ film required for dose delivery was placed in a petri plate with $5 \mathrm{ml}$ of $\mathrm{pH} 6.8$ phosphate buffer. The time taken for the disintegration of the film was measured as the disintegration time. This test was followed in the present study, evaluation was done in triplicates and the standard deviation from the mean value was reported time required for the film to break and disintegrate was noted as in vitro disintegration time.

Table 5: Evaluation of FDFs prepared with natural polymers

\begin{tabular}{|c|c|c|c|c|c|c|}
\hline $\begin{array}{l}\text { Formulation } \\
\text { code }\end{array}$ & $\begin{array}{l}\text { Weight } \\
\text { variation (mg) }\end{array}$ & $\begin{array}{l}\text { Folding } \\
\text { endurance }\end{array}$ & $\begin{array}{l}\text { Content } \\
\text { uniformity (mg) }\end{array}$ & Assay (\%) & $\begin{array}{l}\text { Thickness } \\
(\mu g)\end{array}$ & $\begin{array}{l}\text { Disintegration } \\
\text { time (s) }\end{array}$ \\
\hline FN1 & $64.66 \pm 0.577$ & 155 & $19.88 \pm 0.090$ & 97.4 & $72 \pm 4.47$ & $21.33 \pm 0.577$ \\
\hline FN2 & $78.33 \pm 0.577$ & 160 & $19.94 \pm 0.069$ & 99.8 & $76 \pm 5.47$ & $15.66 \pm 0.577$ \\
\hline FN3 & $61.33 \pm 0.577$ & 160 & $19.85 \pm 0.143$ & 97.0 & $74 \pm 5.47$ & $34 \pm 1.00$ \\
\hline FN4 & $67.66 \pm 0.577$ & 155 & $19.84 \pm 0.126$ & 96.8 & $68 \pm 4.47$ & $48 \pm 1.00$ \\
\hline FN5 & $65.66 \pm 0.577$ & 150 & $19.61 \pm 0.529$ & 97.6 & $56 \pm 5.47$ & $31.66 \pm 0.577$ \\
\hline FN6 & $62.33 \pm 0.577$ & 150 & $19.81 \pm 0.13$ & 96.2 & $64 \pm 5.47$ & $58 \pm 1.00$ \\
\hline FN7 & $74.33 \pm 0.577$ & 160 & $19.94 \pm 0.030$ & 99.6 & $116 \pm 5.47$ & $26.33 \pm 0.577$ \\
\hline FN8 & $87.33 \pm 1.15$ & 165 & $19.50 \pm 0.470$ & 97.3 & $84 \pm 5.47$ & $17.66 \pm 0.577$ \\
\hline FN9 & $73.33 \pm 0.577$ & 160 & $19.90 \pm 0.030$ & 95.4 & $92 \pm 4.47$ & $37.33 \pm 0.577$ \\
\hline FN10 & $71.66 \pm 0.577$ & 155 & $19.80 \pm 0.145$ & 96.3 & $94 \pm 5.47$ & $53.33 \pm 0.577$ \\
\hline FN11 & $70.66 \pm 1.15$ & 165 & $19.61 \pm 0.491$ & 97.2 & $77 \pm 4.47$ & $31.66 \pm 0.577$ \\
\hline FN12 & $68.33 \pm 1.15$ & 160 & $19.79 \pm 0.080$ & 96.5 & $88 \pm 2.73$ & $59.33 \pm 0.577$ \\
\hline
\end{tabular}

Table 6: Evaluation of FDFs prepared with synthetic polymers

\begin{tabular}{llllll}
\hline $\begin{array}{l}\text { Formulation } \\
\text { code }\end{array}$ & $\begin{array}{l}\text { Weight } \\
\text { variation }(\mathbf{m g})\end{array}$ & $\begin{array}{l}\text { Folding } \\
\text { endurance }\end{array}$ & $\begin{array}{l}\text { Content } \\
\text { uniformity }(\mathbf{m g})\end{array}$ & $\begin{array}{l}\text { Assay } \\
(\%)\end{array}$ & $\begin{array}{l}\text { Thickness } \\
(\boldsymbol{\mu g})\end{array}$ \\
\hline FS1 & $128.33 \pm 0.577$ & 150 & $18.88 \pm 0.090$ & 96.2 & $104 \pm 5.47$ \\
FS2 & $97.33 \pm 1.154$ & 150 & $19.12 \pm 0.140$ & 97.0 & $88 \pm 4.47$ \\
FS3 & $92.66 \pm 0.577$ & 160 & $19.64 \pm 0.045$ & 99.7 & $84 \pm 4.47$ \\
FS4 & $89.66 \pm 0.577$ & 150 & $19.0 \pm 0.025$ & 97.5 & $78 \pm 8.94$ \\
FS5 & $120.66 \pm 0.577$ & 155 & $19.16 \pm 0.056$ & $37.65 \pm 0.577$ & 95.2 \\
\hline
\end{tabular}

\section{In vitro dissolution studies}

The in vitro dissolution studies were conducted using $0.1 \mathrm{~N} \mathrm{HCl}$ and $\mathrm{pH} 6.8$ phosphate buffer $(900 \mathrm{ml})$. The dissolution studies were carried out using six basket dissolution apparatus at $37 \pm 0.5^{\circ} \mathrm{C}$ and at $50 \mathrm{rpm}$. Each $2 \times 2 \mathrm{~cm}$ film was submerged into dissolution media. Samples were withdrawn at 1, 3, 5, 10, 15 and
30 min time intervals and filtered through Whatman filter paper and were analyzed spectrophotometrically at $222 \mathrm{~nm}$. To maintain the volume, an equal volume of fresh dissolution medium maintained at same temperature was added after withdrawing samples. The absorbance values were converted to concentration using standard calibration curve previously obtained from the study.

Table 7: Dissolution data of the optimized formulation in $6.8 \mathrm{pH}$ phosphate buffer

\begin{tabular}{ll}
\hline Time (min) & \% drug release \\
\hline 0 & 0 \\
1 & 30.0 \\
3 & 73.0 \\
5 & 86.5 \\
10 & 97.5 \\
15 & 109.3 \\
\hline
\end{tabular}

Table 8: Dissolution data of the optimized formulation in $0.1 \mathrm{~N} \mathrm{HCl}$

\begin{tabular}{ll}
\hline Time (min) & \% drug release \\
\hline 0 & 0 \\
1 & 64.0 \\
3 & 76.8 \\
5 & 91.8 \\
10 & 100.66 \\
15 & - \\
\hline
\end{tabular}




\section{RESULTS AND DISCUSSION}

In the present study, each FDF of $2 \times 2 \mathrm{~cm}$ in size contained $20 \mathrm{mg}$ of Eletriptan hydrobromide. The films were prepared using natural and synthetic polymers, amongst which the films of natural polymers disintegrated faster than the films of synthetic polymers. The films dissolved completely within one minute. The prepared films were tested for various parameters weight variation, thickness, folding endurance, disintegration and dissolution results are showed in table 5. FN2 was chosen as optimized formulation as it had a shortest D. T of $16 \mathrm{~s}$. The dissolution studies were carried out in 6.8 $\mathrm{pH}$ phosphate buffer and $0.1 \mathrm{~N} \mathrm{HCl}, \mathrm{FN} 2$ showed a percentage release of upto $100 \%$ within $10 \mathrm{~min}$ in both mediums.

A comparative study of drug release of optimized formulation and the pure drug was done in $6.8 \mathrm{pH}$ phosphate buffer, and $0.1 \mathrm{~N} \mathrm{HCl}$ which showed the optimized formulation FN2 showed a faster drug release than pure drug as in fig. no 5 and 6.

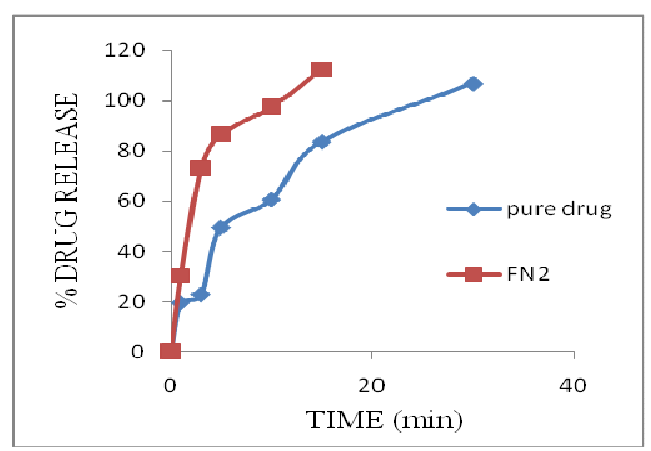

Fig. 5: Comparison of dissolution profiles of optimized film and pure drug EHBR in $6.8 \mathrm{pH}$ phosphate buffer

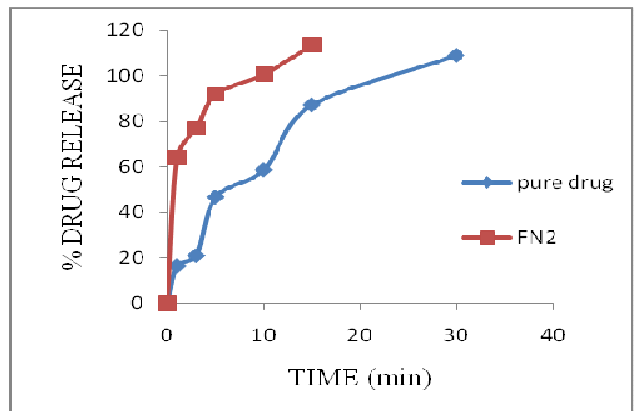

Fig. 6: Comparison of dissolution profiles of optimized film and pure drug EHBR in 0.1N HCl

\section{CONCLUSION}

The optimized FDF FN2 had good mechanical strength, with uniform thickness, high folding endurance, shorter DT and faster dissolution when compared to conventional tablets. The preparation of FDF did not require the addition of any disintegrant separately, so this formulation seems to be an attractive alternative to conventional marketed formulations.

\section{CONFLICT OF INTERESTS}

Declare none

\section{REFERENCES}

1. Rasool Hassan. Overview on drug delivery system. Pharm Anal Acta 2012;3:2153-35.

2. Prasana Desu, Manoranjan Sahu. Formulation and evaluation of fast dissolving films of zolmitriptan. Int Res J Pharm 2012;3:373-6.

3. Alpesh Patel R, Dharmendra Prajapati S, Jignyasha Raval A. Fast dissolving films (FDFs) as a newer venture in fast dissolving dosage forms. Int J Drug Dev Res 2010;2:232-46.

4. Dipika Parmar, Upendra Patel, Bhavin Bhimani, Aditi Tripathi, Dhiren Daslania, Ghanshyam Patel. Orally fast dissolving films as a dominant dosage form for quick release. Int J Pharm Res Bio-sci 2012;1:27-41.

5. Suresh B, Halloran D, James L. Quick dissolving films: a novel approach to drug delivery. Drug Dev Tech; 2006. p. 1-7.

6. Samita Gauri, Gaurav Kumar. Fast dissolving drug delivery and its technologies. Pharma Innovation 2012;1:34-9.

7. Swapnil Patil L, Paresh Mahaparale R, Madhavi Shivnikar A, Shradha Tiwari S, Ketan Pawar V, Prashant Sane N. Fast dissolving oral films: an Innovative drug delivery system. Int J Res Rev Pharm Appl Sci 2012;2:482-96.

8. Dixit RP, Puthli SP. Oral strip technology: overview and future potential. J Cont Release 2009;139:94-107.

9. Gowri R, Narayan N, Revathy S, Prabhavathy G, Preethy Mol G, Rekha G. Melt in mouth films-an effective alternative drug delivery system. Int J Biol Pharm Res 2013;4:645-50.

10. Kai Bin Liew, Yvonne Tze Fung Tan, Kok K Khiang Peh. Characterization of oral disintegrating film containing donepazil for the alzhemier disease. AAPS PharmSciTech 2012;13:134-42.

11. Karthikeyan D, Sanju Sri, Santhosh Kumar C. Development of fast dissolving oral film containing rizatriptan benzoate as an antimigraine medication. Indo Am J Pharm Res 2013;3:2642-54.

12. Indian Pharmacopoeia. Vol 2. Delhi: Government of India ministry of health and family welfare; 2014.

\section{How to cite this article}

- $\quad$ K Pallavi, T Pallavi. Formulation and evaluation of fast dissolving films of eletriptan hydrobromide. Int J Curr Pharm Res 2017; 9(2):59-63. 